\title{
A New Mathematical Approach to Calculate the Area of a Trapezoid
}

\author{
Sunandan Dey* \\ Department of Pharmacy, University of Rajshahi, Rajshahi-6205, Bangladesh \\ *(Corresponding author: sunandandeypharmacy@gmail.com)
}

\begin{abstract}
This mathematical observation deals with the development of a completely new expression $\left[(S / 4 D) \times \sqrt{ }\left\{\left(S_{1}^{2}-D^{2}\right)\left(D^{2}-D_{1}^{2}\right)\right\}\right]$ to calculate the area of a trapezoid system. Because of the difficulties of the previous methods to find out the area of a trapezoid (AOT), the proposed formula has thus indicated the best way to determine the AOT more precisely and easily beyond limitation, successfully. It is obvious that the derived formula is helpful to determine AOT more easily and precisely rather than existing method. And this developed theorem for the trapezoid system is observed for the first time.
\end{abstract}

Keywords: Trapezoid; Area; Height; New formula

\section{INTRODUCTION}

It is obvious that the existing method from the past decade to determine the area of a trapezoidal field is assessed through the adding of two triangles. The area of a triangle is calculated through the Heron's formula [1]. Thus, this method is more intricate. In that case, the ordinary method to calculate the area of a trapezoid (AOT) is also conditional and time consuming.

In another case, when there is given four sides of a trapezoid system, the existing method to calculate the AOT is conditional [2]. This is because, we must need to determine the height. There is no formula to calculate the AOT without height. Therefore, there is a limitation of the existing formula.

In 1990, Lucille Lohmeier Peterson et. al. presented several ways to find out the area of trapezoid, but he didn' t discuss the method to calculate the AOT beyond height of the trapezoid [3]. In 2014, Manizade et al. also discussed the way to find out the area of a trapezoid through the ordinary method [4]. That's why, in every case, the determination of the AOT is conditional. To eliminate the limitation of the existing method, we have tried to calculate the AOT. And we have been successful to determine AOT through mathematical evaluation. In this case, we have 
developed a new formula to find out the AOT. In this mathematical study, we proceed through a mathematical approach to eliminate the height from the existing formula. In this sense, we have obtained a mathematical correlation between the height and sides of a trapezoid system. So, it is cleared that we can easily eliminate the height to determine the AOT. Thus, our proposed method provides a completely new formula to calculate the AOT without calculating height. Therefore, our proposed method is more convenient to compute the AOT in a better way. And our proposed formula is also evaluated through numerical analysis in comparison with existing formula. Moreover, our proposed formula displays an alternative and interesting way to calculate the AOT in the absence of height finding. Finally, it is obvious that, in case of given four sides of a trapezoid, we must need to determine the height of the trapezoid [2], [5]. And we do not need to rely on the propaganda. To sum up, this mathematical study is completely successful and precise for developing the new formula for the trapezoid system with zero limitation in comparison with existing method.

\section{THEORY AND DISCUSSION}

Methodology: The mathematical observation is studied on the basis of Heron's formula and ordinary formula [1], [2].

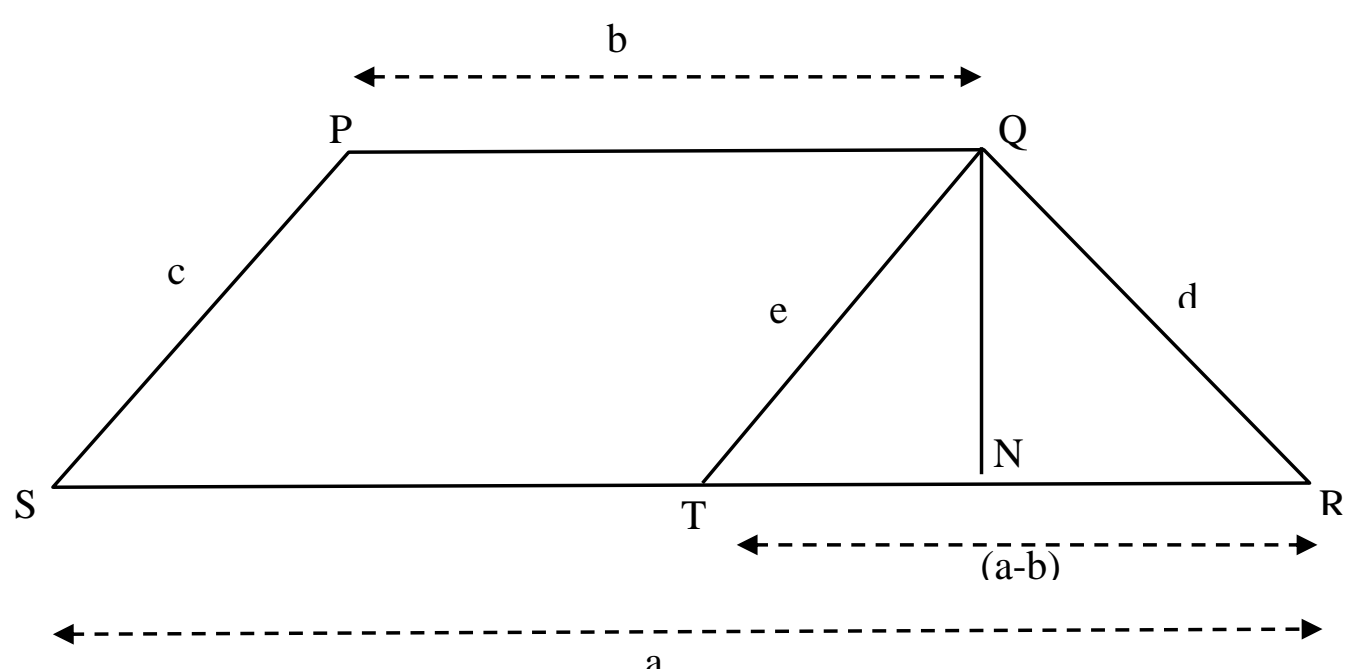

Figure-1: PQRS Trapezoid

Let PQRS be a trapezoid, we have to develop the formula for calculating the area. 
PQRS is a trapezoid [Fig. 1] to which PQ and RS are parallel sides; PS and QR are oblique sides. By cutting the $\mathrm{ST}$ equal to $\mathrm{PQ}$ from $\mathrm{RS}$ side i.e. $\mathrm{PQ}=\mathrm{ST}$

Now, PQ \| RS i.e. PQ \|ST, and PQ = ST. So PQTS is a parallelogram. PS $\|$ QT and PS=QT.

Let, $\mathrm{RS}=\mathrm{a}, \mathrm{PQ}=\mathrm{b}, \mathrm{PS}=\mathrm{c}, \mathrm{QR}=\mathrm{d}$. so, $\mathrm{RT}=\mathrm{RS}-\mathrm{ST}=\mathrm{a}-\mathrm{b}=\mathrm{e}$ (let), height $\mathrm{QN}=\mathrm{h}$ (let)

The area of the trapezoid is, $(1 / 2) \times(\mathrm{a}+\mathrm{b}) \times \mathrm{h}$; according to ordinary method.

The area of the trapezoid is, $(\mathrm{S} / 4 \mathrm{D}) \times \sqrt{ }\left\{\left(\mathrm{S}_{1}{ }^{2}-\mathrm{D}^{2}\right)\left(\mathrm{D}^{2}-\mathrm{D}_{1}{ }^{2}\right)\right\}$; according to the proposed method, where, $S=a+b, S_{1}=c+d, D=a-b, D_{1}=c-d$

Proof: In triangle QRT, QN is height $(\mathrm{QN}=\mathrm{h})$

The half of the perimeter of QRT triangle,

$$
\begin{aligned}
& \mathrm{s}=\{(\mathrm{a}-\mathrm{b})+\mathrm{d}+\mathrm{c}\} / 2 \\
& =(\mathrm{c}+\mathrm{d}+\mathrm{e}) / 2 ; \mathrm{a}-\mathrm{b}=\mathrm{e}
\end{aligned}
$$

The area of the triangle QRT is

$$
\begin{aligned}
& \sqrt{ }\{\mathrm{s}(\mathrm{s}-\mathrm{c})(\mathrm{s}-\mathrm{d})(\mathrm{s}-\mathrm{e})\} \\
= & \sqrt{ }[\{(\mathrm{c}+\mathrm{d}+\mathrm{e}) / 2\}\{(\mathrm{c}+\mathrm{d}+\mathrm{e}) / 2-\mathrm{c}\}\{(\mathrm{c}+\mathrm{d}+\mathrm{e}) / 2-\mathrm{d}\}\{(\mathrm{c}+\mathrm{d}+\mathrm{e}) / 2-\mathrm{e}\}] \\
= & (1 / 4) \times \sqrt{ }\{(\mathrm{c}+\mathrm{d}+\mathrm{e})(\mathrm{c}+\mathrm{d}-\mathrm{e})(\mathrm{e}+\mathrm{c}-\mathrm{d})(\mathrm{e}-\mathrm{c}+\mathrm{d})\} \\
= & (1 / 4) \times \sqrt{ }\left[\left\{(\mathrm{c}+\mathrm{d})^{2}-\mathrm{e}^{2}\right\}\left\{\mathrm{e}^{2}-(\mathrm{c}-\mathrm{d})^{2}\right\}\right. \\
= & (1 / 4) \times \sqrt{ }\left\{\left(\mathrm{S}_{1}{ }^{2}-\mathrm{D}^{2}\right)\left(\mathrm{D}^{2}-\mathrm{D}_{1}{ }^{2}\right)\right\}, \text { where } \mathrm{c}+\mathrm{d}=\mathrm{S}_{1}, \mathrm{e}=\mathrm{a}-\mathrm{b}=\mathrm{D}, \mathrm{c}-\mathrm{d}=\mathrm{D}_{1}
\end{aligned}
$$

Now if the height of triangle is $h$ then, $(1 / 2) \times h \times(a-b)=(1 / 4) \times \sqrt{ }\left\{\left(S_{1}^{2}-D^{2}\right)\left(D^{2}-D_{1}^{2}\right)\right\}$

$$
\text { Or, h }=\{1 /(2 \mathrm{D})\} \times \sqrt{ }\left\{\left(\mathrm{S}_{1}^{2}-\mathrm{D}^{2}\right)\left(\mathrm{D}^{2}-\mathrm{D}_{1}{ }^{2}\right)\right.
$$

Therefore, the area of the trapezoid is, $(1 / 2) \times(a+b) \times h$

$$
\begin{gathered}
=(1 / 2) \times S \times\{1 /(2 \mathrm{D})\} \times \sqrt{ }\left\{\left(\mathrm{S}_{1}^{2}-\mathrm{D}^{2}\right)\left(\mathrm{D}^{2}-\mathrm{D}_{1}{ }^{2}\right)\right\} \\
=(\mathrm{S} / 4 \mathrm{D}) \times \sqrt{ }\left\{\left(\mathrm{S}_{1}^{2}-\mathrm{D}^{2}\right)\left(\mathrm{D}^{2}-\mathrm{D}_{1}^{2}\right)\right\}
\end{gathered}
$$




\section{CALCULATION AND RESULTS}

Let the two parallel sides of a trapezoid be $91 \mathrm{~cm}$ and $51 \mathrm{~cm}$, the transverses sides is $37 \mathrm{~cm}$ and $13 \mathrm{~cm}$. We have to find out the area of the trapezoid.

Solution in ordinary method [2], [5],

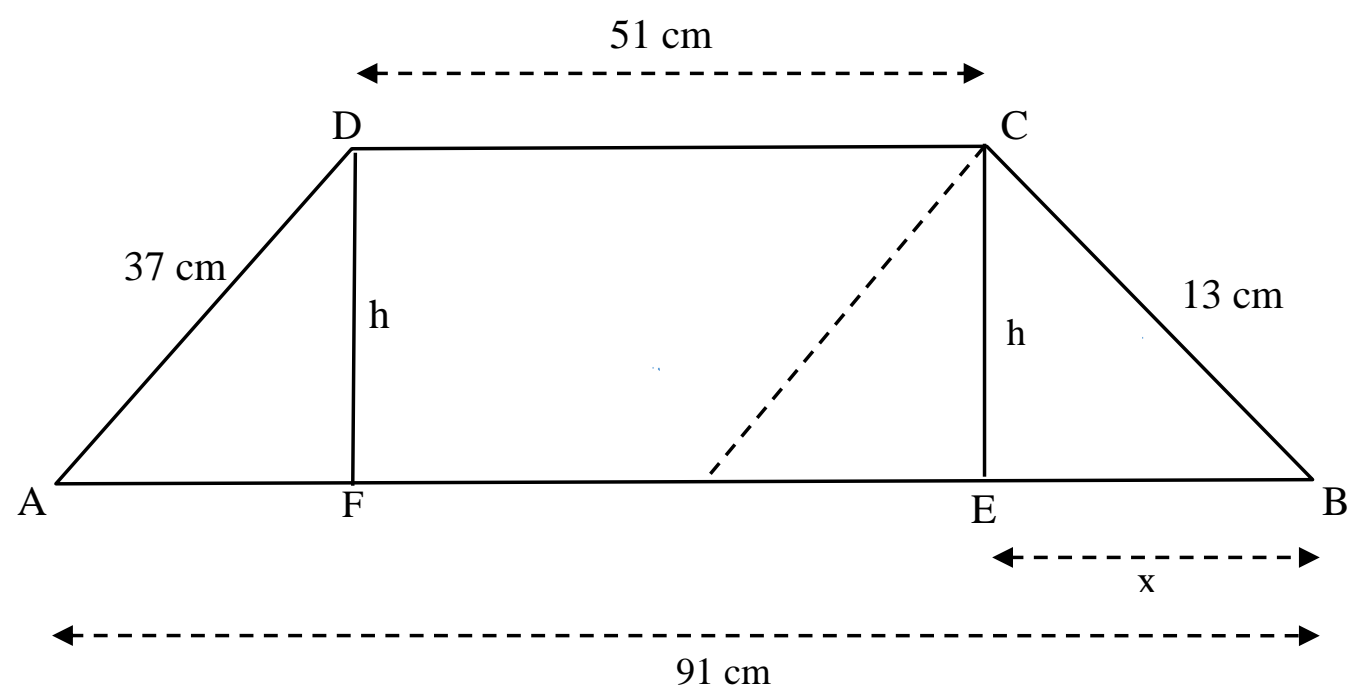

Figure-2: ABCD Trapezoid

If $\mathrm{ABCD}$ is a trapezoid [Fig. 2] to which the parallel side $\mathrm{AB}$ is $91 \mathrm{~cm}$ and $\mathrm{DC}$ is $51 \mathrm{~cm}$

And the other two sides $\mathrm{AD}$ is $37 \mathrm{~cm}$ and $\mathrm{BC}$ is $13 \mathrm{~cm}$.

Let the height be $\mathrm{DF}=\mathrm{CE}=\mathrm{h} \mathrm{cm}$ and $\mathrm{EB}=\mathrm{x}$,

$$
\begin{aligned}
\mathrm{AF} & =\mathrm{AB}-\mathrm{BE}-\mathrm{EF} \\
& =91-\mathrm{x}-51 \\
& =(40-\mathrm{x}) \mathrm{cm}
\end{aligned}
$$

In right angled triangle $\mathrm{EBC}, \mathrm{BC}^{2}=\mathrm{CE}^{2}+\mathrm{EB}$,

$$
\text { Or, } 13^{2}=h^{2}+x^{2}
$$




$$
\text { Or, } h^{2}=13^{2}-x^{2}
$$

Again, right angled triangle $\mathrm{ADF}, \mathrm{AD}^{2}=\mathrm{AF}^{2}+\mathrm{DF}^{2}$

$$
\begin{aligned}
& \text { Or, } 37^{2}=(40-x)^{2}+h^{2} \\
& \text { Or, } h^{2}=37^{2}-(40-x)^{2}
\end{aligned}
$$

Now, we get from the equation (1) and (2), $13^{2}-x^{2}=37^{2}-(40-x)^{2}$

$$
\begin{aligned}
& \text { Or, } 80 x=400 \\
& \text { Or, } x=5
\end{aligned}
$$

$$
\begin{gathered}
\text { Now, } h^{2}=13^{2}-5^{2} \\
\text { Or, } h=12
\end{gathered}
$$

The area of the trapezoid equals, $(1 / 2) \times(\mathrm{AB}+\mathrm{CD}) \times \mathrm{h}$

$$
\begin{gathered}
=(1 / 2) \times(91+51) \times 12 \\
=852 \mathrm{~cm}^{2}
\end{gathered}
$$

Again, by applying the proposed method-

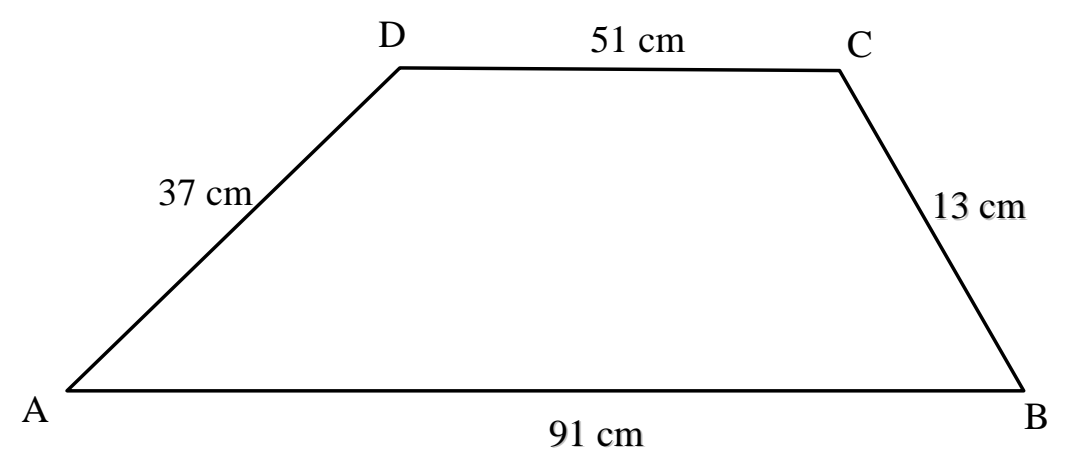

Figure-3: ABCD Trapezoid

Here [Fig. 3] the summation of the parallel two sides is, $S=A B+C D$

$$
\begin{aligned}
& =91+51 \\
& =142 \mathrm{~cm}
\end{aligned}
$$

The difference, $\mathrm{D}=\mathrm{AB}-\mathrm{CD}$, where $\mathrm{AB}>\mathrm{CD}$

$$
=40 \mathrm{~cm}
$$


The summation of the two oblique sides is, $\mathrm{S}_{1}=\mathrm{AD}+\mathrm{CB}$

$$
\begin{aligned}
& =37+13 \\
& =50 \mathrm{~cm}
\end{aligned}
$$

So the area of the trapezoid is $(\mathrm{S} / 4 \mathrm{D}) \times \sqrt{ }\left\{\left(\mathrm{S}_{1}{ }^{2}-\mathrm{D}^{2}\right)\left(\mathrm{D}^{2}-\mathrm{D}_{1}{ }^{2}\right)\right\}$

$$
\begin{aligned}
& =\{142 /(4 \times 40)\} \times \sqrt{ }\left\{\left(50^{2}-40^{2}\right)\left(40^{2}-24^{2}\right)\right\} \\
& =(142 / 160) \times \sqrt{ }(900 \times 1024) \\
& =(142 / 160) \times 960 \\
& =852 \mathrm{~cm}^{2}
\end{aligned}
$$

Thus, this mathematical analysis observes the importance and application of the proposed formula through the comparison with the ordinary formula with the help of an example. This evaluation gives a numerical evidence for our proposed method and bitterness of the ordinary method as well. So it is obvious that the proposed formula is completely correct.

\section{CONCLUSION}

Prior to this study, there was actually no alternative method to determine the AOT in such an effective and easiest way. This paper initiatively focuses on the results and gives also numerical evidence in comparison with the existing formula. Due to the massive difficulties for using ordinary method, the newly proposed method would be much more initiative for research and mathematical community, and could be an interesting new work where the value of AOT actually used as well.

\section{REFERENCES}

[1]. Bernard M Oliver: Heron's Remarkable Triangle Area Formula, Mathematics Teacher 86 (2), 160-63, 1993. 
[2]. Wilfred H Hinkel: The trapezoid-and area, The Mathematics Teacher 53 (2), 106-108, 1960.

[3]. Lucille Lohmeier Peterson, Mark E Saul: Seven ways to find the area of a trapezoid, The Mathematics Teacher 83 (4), 283-286, 1990.

[4]. Manizade, A. G., \& Mason, M. M. : Developing the area of a trapezoid. MatheMatics teacher, 107(7), 508-514, 2014.

[5]. Darko Veljan: The 2500-year-old Pythagorean theorem, Mathematics Magazine 73(4), 259$272,2000$. 